\title{
Swarm Intelligence: \\ Establishing Behavioral Norms for the Emergence of Collective Leadership
}

Eric J. McNulty, M.A.

Director of Research and Professional Programs

National Preparedness Leadership Initiative (NPLI)

Harvard T.H. Chan School of Public Health

Barry C. Dorn, M.D., M.P.H.M.

Associate Director

National Preparedness Leadership Initiative (NPLI)

Harvard T.H. Chan School of Public Health

Eric Goralnick, M.D., M.S.

Medical Director, Emergency Preparedness

Brigham and Women's Healthcare

Richard Serino

Distinguished Visiting Fellow

National Preparedness Leadership Initiative (NPLI)

Harvard T.H. Chan School of Public Health

Jennifer O. Grimes, M.A., M.D. Candidate

Brown University Warren Alpert Medical School

Lisa Borelli Flynn, J.D., M.P.H.

Research Associate

National Preparedness Leadership Initiative (NPLI)

Harvard T.H. Chan School of Public Health

Melani Cheers, MD

Director

Health Services at Ross University School of Medicine

Leonard J. Marcus, PhD

Director

National Preparedness Leadership Initiative (NPLI)

Harvard T.H. Chan School of Public Health 


\begin{abstract}
To explicate the qualities of cooperation among leaders and their organizations during crisis, we studied the response to the 2013 Boston Marathon bombings. Through interviews and analysis, we discovered leaders successfully overcame obstacles that typically undermine collective crisis response. Qualitative analysis revealed five guiding behavioral principles that appeared to stimulate effective inter-agency leadership collaboration in high stakes. We draw upon concepts of collective leadership and swarm intelligence to interpret our observations and translate the findings into leader practices. We focus on replicable aspects of a metaphenomenon, where collective action was greater than the sum of its parts; we do not evaluate individual leader behavior. Our findings provide a starting point for deeper exploration of how to bolster public safety by catalyzing enhanced inter-agency leadership behavior.
\end{abstract}

\title{
Introduction
}

A crisis is "a low-probability, high-impact event that threatens the viability of the organization and is characterized by ambiguity of cause, effect, and means of resolution, as well as by a belief that decisions must be made swiftly" (Pearson \& Clair, 1998, p. 60). They are increasingly common, far-reaching in impact, unpredictable, and without definite conclusion on a short time scale (Boin \& 't Hart, 2003). While a crisis may affect an organization or a population, effective management is critical to a successful outcome in which "key stakeholders believe that the success outcomes of short- and long-range impacts of crises outweigh the failure outcomes" (Pearson \& Clair, 1998, p. 61). The realities of the crisis strain pre-existing structures, thereby complicating the work of leaders. Therefore, crisis leadership has rightly garnered much attention from researchers seeking to understand which aspects of leadership generate a successful response.

We chose a single case study to examine a response that appeared both effective and well-coordinated. Through contemporaneous observation and follow-up analysis, we examined leaders of the Boston Marathon bombing response (hereafter referred to as the "Boston response"). The Boston response required high-consequence decisions and actions hinging on quick and agile intra- and inter-organizational coordination, and was deemed successful (Massachusetts Emergency Management Agency [MEMA], et al., 2014). In this paper, we explore a leadership phenomenon we found that is distinct from most incidents: while commandand-control hierarchies functioned within individual entities, no one individual or organization assumed operational command of the overall effort. Executive leaders of diverse organizations led together and demonstrated extraordinary cooperation and collaboration, linking and leveraging their knowledge, assets, and operations to create valuable synergy, thereby enabling the overall Boston response to be more effective than the sum of its component parts.

The concept of collectivistic leadership (Yammarino, Salas, Serban, Shirreffs, \& Shuffler, 2012) provides an umbrella for leadership theories focused on collective effort, such as shared leadership, collective leadership, team leadership, and others. Yammarino et al. (2012) define collectivistic leadership as, "multiple individuals interact through a variety of formal and informal structures, broadly defined, and take on a variety of leadership roles, both formally and informally over time." These concepts are relevant because-despite the commonly accepted "centralization thesis," or belief that one person is in charge of the overall effort—in fact "[c]risis 
operations are multi-organizational, trans-jurisdictional, polycentric response networks. Crises demand lateral coordination, not top-down command and control'" (Boin \& 't Hart, 2003, p. 547). Therefore, crisis leaders must flexibly integrate multiple networks, guiding participants toward an effective synergistic response.

Response teams confront complex and evolving challenges utilizing highly distributed influences in organizational leadership structures, which are necessary in the face of situations too complex for traditional hierarchical management (e.g., Ancona, Bresman, \& Caldwell, 2009; D'Innocenzo, Mathieu, \& Kukenberger, 2014; Pearson \& Clair, 1998; Wang, Waldman, \& Zhang, 2014). Drescher, Korsgaard, Welpe, Picot, and Wigand (2014, p. 772) describe this leadership process with reference to Pearce and Conger (2003, p. 1): "a dynamic, interactive influence process among individuals in groups for which the objective is to lead one another to the achievement of group or organizational goals." This adaptive process is leveraged to raise the necessary skills, expertise, and resources to address the ever-changing demands of a crisis (Hadley, Pittinsky, Sommer, \& Zhu, 2011; Schoenberg, 2004) and to reduce error through consensus-forming (Combe \& Carrington, 2015).

Despite this, effective collective leadership does not always emerge during crises. "Organizational chaos, media pressure, stress, and inaccurate information are but a few factors that make it very hard for crisis leaders to make sound decisions ..." (Boin \& ' $t$ Hart, 2003, p. 545). Pearson and Clair (1998) concur, noting that while a loss of "shared meaning, legitimization, and institutionalization of socially constructed relationships" (p. 63) are intrinsic to a crisis, "[a]mbiguity of cause, effect, and means of resolution... will lead to disillusionment or loss of psychic and shared meaning, as well as to the shattering of commonly held beliefs and values and individuals' basic assumptions" (p. 66). Additionally, "[t]he simultaneous, stressful interaction within and outside an organization during a crisis can promote conflict (Mitroff \& Kilmann, 1984)" (p.71).

The interpersonal challenges of a crisis are self-perpetuating and self-enhancing. Thus, it seems counterintuitive that adding more players - with potentially conflicting values - to a situation characterized by chaos would improve outcomes. The emergence of shared leadership is a time-consuming process (Combe \& Carrington, 2015; D'Innocenzo et al., 2014; Drescher et al., 2014) and crises unfold and change quickly (Leonard \& Howitt, 2012; Robert \& Lajtha, 2002). Further, increasing task complexity may make shared leadership a liability (D'Innocenzo et al., 2014), even though it is both common in crisis response (e.g., Leonard \& Howitt, 2012) and necessary (Hadley et al., 2011; Robert \& Lajtha, 2002). Therefore, overcoming the obstacles to shared leadership introduced by crises appears critical to enhancing crisis leader response.

This study contributes significantly to existing theoretical and practical understanding of crisis leadership by identifying and describing specific behavioral norms, part of a "missing language of competence" (Pearce \& Conger, 2003) for collective and shared leadership. The findings can guide leaders to prepare for and execute rapid emergence of efficacious leader collaboration during stressful and chaotic events. The Boston response also provides an opportunity to inform and translate theoretical collective leadership models as applied to 
pragmatic leader behaviors. The intent is to overcome the inherent obstacles that confound emergent collective leadership in real-world crises.

Background. On April 15, 2013, more than twenty-four thousand runners participated in the $117^{\text {th }}$ Boston Marathon. Approximately one million spectators lined the 26.2-mile course. At 2:49 p.m., two improvised explosive devices (IEDs) detonated near the finish line. Three bystanders died instantly. Two-hundred sixty-four injured were sent to more than 20 hospitals in the greater Boston area. Despite grievous injuries, all survived (Goralnick et al., 2015).

The executive leadership team included elected officials and the heads of public safety agencies and affected private and nonprofit organizations. They faced two major crises within one week: the first was Monday's bombings and the immediate aftereffects including survivor care, public safety, and mounting an intensive investigation. In the moments after the blasts, traditional hierarchies and command structures were evident and functioned well, aided by widespread public engagement and cooperation. By approximately 3:30 p.m., a joint command was coordinating situational assessment and decision-making across agencies and jurisdictions, consistent with theoretical characterizations of an effective shared crisis leadership (Ancona \& Backman, 2010b; D’Innocenzo et al., 2014; Wang, Waldman \& Zhang, 2014).

The second event began on Thursday night when these same executive leaders encountered a dangerous, rapidly escalating situation culminating with a violent confrontation with the bombing suspects. Multiple law enforcement agencies self-deployed in an initially uncoordinated response. Responders described the scene as "chaos," a word none used to describe the Monday bombings. Having experienced the advantages of cross-agency collaboration, when leaders converged they immediately established a joint command to coordinate decision making and operational responsibilities. They quickly established order. A manhunt on Friday closed much of the Boston metropolitan area. The event ended with the death of one suspect and capture of the second.

The leadership dynamics that emerged immediately after the bombings survived evolving complexities of the response and the attendant psychological stress, time pressure, and logistical complications (MEMA et al., 2014). Cooperativity was stable and even increased between Monday and Friday, despite the uncertainty and turmoil that arose. Under the moniker "Boston Strong," the city demonstrated noteworthy resilience. While not perfect, the Boston response provides an important benchmark for leaders of future responses (Leonard \& Howitt, 2013).

\section{Method}

In this preliminary study, we chose qualitative analysis to afford the necessary sensitivity and flexibility to accommodate new, non-prototypical, and empirically underdetermined themes (Buchanan \& Bryman, 2011, p. 295). Creswell (2014) recommends a research process using a flexible, adaptable, and iterative approach to data collection and analysis, particularly to preserve participants' meaning and avoid superimposition of the researchers'. We conducted a literature review to inform analysis of the anomaly found in the Boston response: emergence of exceptional leadership cooperativity despite the observed lack of centralized operational 
command. We begin with this review to lay the groundwork for a central premise of our analysis: the emergence of swarm-like intelligence among these leaders.

Scholarship exploring the many variants of collectivistic leadership provided insights into theoretical constructs that could explain how such an outcome could occur. Yet, they did not fully explain the specific behaviors that facilitated the cooperativity and outcomes achieved in the Boston response. One of the authors with a personal interest in birding suggested the behaviors resembled the murmurations of starlings, complex aerial maneuvers involving as many as tens of thousands of birds marked by "strong spatial coherence and show extremely synchronized maneuvers, which seem to occur spontaneously, or in response to an approaching threat ..." (King \& Sumpter, 2012). This led to looking beyond the leadership literature to the scholarship on swarm intelligence (e.g. Miller, 2007) for a cross-fertilization of ideas. Although more a biological rather than a topic of social scientific inquiry, swarm intelligence is rooted in behaviors: simple rules and social cues that enable non-human species to engage in complex social behavior without any individual directing the action. Our observations and conclusions are informed by these two disparate yet complementary fields of study.

We employed grounded theory methodology (Glaser \& Strauss, 1967) as it focuses on "the relationship of the individual or collective experience to society, to history, the group or the organization" (Goulding, 2009, p. 381) and because it allows these pervasive qualities to emerge without preconceived ideologies impinging upon and confounding the emergent theory (Buchanan \& Bryman, 2011; Glaser, 2009). Though we begin this paper with our literature review, this study otherwise follows grounded theory format in presenting first the facts of the incident followed by an iterative analysis of emergent qualities. In accordance with process learning, we refrained from introducing qualitative data analysis elements such as "interview guides, sampling, taping and preconceived analysis" said to "block" grounded theory (p. 4), and a preliminary literature review, which imposes a priori assumptions about the theoretical framework into which the data should fit (Glaser, 2009). We focus on replicable aspects of the meta-phenomenon: collective action effectiveness was greater than the sum of its parts, so we did not perform an evaluation of the actions of any individual leader.

We utilized purposive sampling, selecting a specific population of interest to allow for focus on particular characteristics without the introduction of extraneous error variables ascribed to sample heterogeneity. Critical case sampling is a type of purposive sampling that is widely recommended for exploratory studies or in research in which a single case can be "decisive in explaining the phenomenon of interest" ("Purposive sampling," n.d.). It is especially useful in model construction (e.g., Buchanan \& Bryman, 2011; Eisenhardt, 1989). We followed Schofield's recommendation (2002, in Schutt, 2015) to choose sites based on their fit with a typical situation in order to increase the generalizability of nonprobability sampling: in this case both a specific event and participants who occupied particular positions in that event, and who represented the range of points of view, and were especially knowledgeable about the issues being investigated (Schutt, 2015). Such purposive sampling is more conducive to detection of trends demonstrated within a population rather than large and random samples whose internal variance may be mistakenly attributed to the phenomenon of interest (Benbasat, Goldstein, \& Mead, 1987; Daniel, 2011; "Purposive sampling," n.d; Schutt, 2015). This method provides a focused yet comprehensive framework for exploratory research. 
Individual interview participants, aged 35-64 years, held senior managerial and executive roles (see Table 1). They were willing to speak with study investigators by acquaintance with the National Preparedness Leadership Initiative (NPLI) program and through contacts of those affiliated with NPLI (NPLI, 2013). Participants included Massachusetts Governor Deval Patrick, Boston Mayor Thomas Menino, senior federal, state, and local first responders, as well as executives from the non-profit and private sector organizations. When these leaders suggested inclusion of an additional individual, we sought an interview. Sample development was an iterative process and continued until we reached saturation with no further themes emerging.

Table 1

Number of Interview Participants by Sector

\begin{tabular}{lc}
\hline \multicolumn{1}{c}{ Sector } & Interviewees \\
\hline Law Enforcement & 7 (4 local, 1 state, 2 federal $)$ \\
Fire & 1 \\
Emergency Medical Services & 1 \\
Private sector & 4 \\
Political & 2 (1 local, 1 state $)$ \\
Other Governmental & 5 (1 local, 2 state, 2 federal) \\
Non-governmental Organizations & 2 \\
\hline
\end{tabular}

We employed semi-structured interviews to foster situational flexibility and multiple influences (Buchanan \& Bryman, 2011; Packer, 2010). We conducted 22 interviews between late April and November 2013 in order to assess the impact of leadership thinking and actions on the efficacy of the response (Martin \& Turner, 1986). As leader behaviors and outcomes were our primary focus, we assessed responses at multiple time points and from multiple perspectives (Buchanan \& Bryman, 2011; Orr, 1996). It is important to understand how participants processed their actions and that of the inter-agency response, as these ideational forces that create the institution itself (DiMaggio \& Powell, 1983, in Buchanan \& Bryman, 2011).

At least two and up to four researchers attended each interview, so multiple interviewers could affirm inter-rater reliability and accurate recording (or triangulation from both multiple sources and multiple investigators, as in Gibbert \& Ruigrok, 2010). During interviews, researchers took longhand notes. In accordance with prescribed procedure and in respect to participant wishes, interviews were not electronically recorded. Prior to the first presentation of these data in publication, participants consented to the release of information provided, iteratively contributed information, verbally checked research conclusions with study investigators, and previewed comments in-context (Marcus, McNulty, Dorn, \& Goralnick, 2014). The member-checking system allows participants to clarify statements, affirm or refute research conclusions, and refine perspectives assumed in the study according to their expertise and phenomenological experience (Lincoln \& Guba, 1985).

In line with grounded theory methodology, we analyzed notes using an open coding process that revealed emergent themes. Through subsequent axial coding, sub-themes within and interdependencies between each of these were identified. Emerging from this analysis was a 
remarkable phenomenon that is the focus of this paper: no one person appeared to be in overall operational command yet exceptional cooperativity was evident. Several study participants confirmed the validity of this theme.

\section{Results}

Interviewees attributed the positive outcome of the Boston response to a variety of interrelated factors including: volunteers responding quickly to assist the injured; medical personnel transforming a first aid tent into a mass-casualty triage unit; efficient pre-hospital care, coordination, and even distribution of the injured among local hospitals by Boston Emergency Medical Services (EMS); simultaneous mobilization of medical teams across the city; efficient hospital management of incoming patient flow; rapid securing of the blast sites and initiation of the investigation; and cooperation among law enforcement agencies for efficient evacuation of the affected areas. Interviewees credited the extensive, multi-year commitment to interagency planning, exercises, and drills to explain both the operational efficacy and the collaborative spirit.

Analysis of our interviews about the Boston response revealed five behavioral themes deemed crucial to the successful emergence of collective leadership within a leadership team, and which articulate normative behaviors from which collective leadership may be more likely to arise. They are presented here in their order of mention during interviews: 1) unity of mission; 2) generosity of spirit; 3) stay in your lane; 4) no ego-no blame; and 5) a strong foundation of trusted relationships (See Table 2).

\section{Table 2}

Swarm Leadership Behavioral Themes and Examples

\begin{tabular}{ll}
\hline \multicolumn{1}{c}{ Swarm Leadership Behavioral Theme } & \multicolumn{1}{c}{ Study Example } \\
\hline Unity of Mission & $\begin{array}{l}\text { "Saving lives" consistently referred to as } \\
\text { shared animating purpose driving thinking, } \\
\text { decisions, and actions across all responding } \\
\text { sectors. }\end{array}$ \\
Generosity of Spirit and Action & $\begin{array}{l}\text { Despite continued risk, hundreds of volunteers } \\
\text { and first responders assisted the wounded and } \\
\text { spectators. }\end{array}$ \\
& $\begin{array}{l}\text { Secret Service responded to a reported third } \\
\text { bombing at the John F. Kennedy Library at } \\
\text { Boston Police Department's (BPD) request. }\end{array}$ \\
& $\begin{array}{l}\text { Massachusetts National Guard troops worked } \\
\text { under the jurisdiction of BPD to provide transit } \\
\text { security. }\end{array}$ \\
\hline
\end{tabular}




\begin{tabular}{|c|c|}
\hline & $\begin{array}{l}\text { Without prompting, community members } \\
\text { provided food and water to searchers during the } \\
\text { Watertown manhunt. }\end{array}$ \\
\hline \multirow[t]{2}{*}{ Stay in Your Lane } & $\begin{array}{l}\text { High level of respect for local, state and federal } \\
\text { jurisdictional considerations as the event's } \\
\text { scope transcended typical boundaries, even } \\
\text { when operational issues could have led to } \\
\text { friction. For example, BPD oversaw the crime } \\
\text { scene while FBI oversaw the investigation; FBI, } \\
\text { Watertown Police, and other law enforcement } \\
\text { deferred to BPD during Watertown arrest, an } \\
\text { event outside of BPD's formal jurisdiction and } \\
\text { part of a Federal terrorism investigation. }\end{array}$ \\
\hline & $\begin{array}{l}\text { This sensitivity extended to interactions } \\
\text { between the Governor and Mayor. Incapacitated } \\
\text { due to a medical condition, the Mayor was } \\
\text { unable to participate fully in decision-making. } \\
\text { The Governor diplomatically included the } \\
\text { Mayor, though at times reached decisions alone } \\
\text { that otherwise would be collaborative. }\end{array}$ \\
\hline No-Ego, No Blame & $\begin{array}{l}\text { Lack of ego-driven or blame-casting behaviors. } \\
\text { Comments reflected exceptional cooperativity } \\
\text { and collaboration. For example, leaders } \\
\text { carefully orchestrated press conferences to } \\
\text { convey the collaborative tenor of the working } \\
\text { relationships. }\end{array}$ \\
\hline Foundation of Trusted Relationships & $\begin{array}{l}\text { Consistent reference to long-standing } \\
\text { relationships, joint exercises and training, and } \\
\text { personal histories contributing to high levels of } \\
\text { trust in inter-personal and inter-organizational } \\
\text { interactions and joint decision-making. }\end{array}$ \\
\hline
\end{tabular}

The shared mission, "save lives," was explicitly stated as a guiding principle allowing individuals with diverse roles in different organizations to operationalize toward that goal effectively. Similarly, "generosity of spirit and action" commonly emerged with numerous acts of selfless behavior. "Stay in your lane" characterized respect for and deference to formal authorities and responsibilities among organizations. Participants described a principle of "no ego-no blame," as the overarching recognition that they would either succeed or fail together. The leaders stressed the importance of mutual support, particularly in quickly reaching agreement on difficult decisions. Many leaders noted their agencies' extensive history of working together facilitated such dynamics in this crisis. This "strong foundation of trusted 
relationships" resulted from an enduring and consistent tradition of public-private and crossagency partnerships in the Boston metropolitan area.

To further understand how these themes fit into the larger context of leadership scholarship and how they may enrich our understanding of dynamic leadership structures, we compared them with extant literature. We found that leaders described a collective form of leadership, and the system they adopted also demonstrated features of swarm intelligence. We explored the interrelationships of these fields with our observations from the interviews and the five emergent themes to situate our findings and explicate the features of this response that contributed to its success.

\section{Discussion}

When all interviews were analyzed, it became clear that while jurisdictional and functional responsibilities were divided among entities and their leaders, no one organization or leader held overall operational command. Though this may seem to be a formula for chaos, the result was quite the opposite. A self-organized, adaptive ad hoc leadership structure emerged, enabling highly coordinated activity across the multi-team organizational system. It was described using terms and phrases consistent with the general properties of "collectivistic leadership" (Yammarino et al., 2012), defined above. Group actions are better described as the result of collective cognition, or similar pattern recognition and definition (Gibson, 2001) - i.e. what was happening - and shared mental models, a common understanding of system purpose, structure, and function (Rouse \& Morris, 1986) - i.e. what was to be done - among the individuals who form the leadership group, rather than as a sum of incongruent individual actions (Rolling, 2013). There also was evidence of "teaming," the ability to fluidly form and dissolve leadership working groups as needed in order to solve specific problems (Edmondson, 2012). The measure of their collective leadership effectiveness was in lives saved, suspects captured, public confidence maintained, and population resilience fostered.

For example, when asked who was "in charge," several executive-level respondents named Massachusetts Governor Patrick. Yet, the Governor responded to this question by naming the FBI Special Agent in Charge (SAC). In one of our last interviews, we asked the FBI $\mathrm{SAC}$ about his role in the decision to leave the public transit system open after the bombing. He replied that he was not present for this decision, and clarified he was in charge only of the criminal investigation and not the whole operation. When we then asked the SAC who was in charge of the overall operation, he answered, "I guess no one."

Collective Leadership. Our analysis benefits from the shift in recent years of the focus of leadership research "from understanding the actions and interactions of 'leaders' to understanding the emergent, informal, and dynamic 'leadership' brought about by the members of the collective itself" (Contractor, et al., 2012, p. 994). This growing body of scholarly work explores various leadership approaches that mirror our analysis of the Boston response, that is, according to Yammarino et al. (2012), approaches that are:

... not solely or primarily leader-centric, not constrained by formal power and authority structure and relationships, not limited to leader-to-follower interactions in small groups 
and teams, involve more than typical leader behaviors or team skills, incorporate a variety of formal and informal organizational and extra-organizational arrangements, tend to be dynamic and non-linear in nature, and strive to be responsive to complex, rapidly changing and uncertain problems and environments . . e.g., crisis situations. (pp. 395397)

We use the term "collective leadership" for simplicity in this discussion, as our intent here is not to parse the distinctions between theoretical approaches, but rather to better understand behaviors contributing to cohesive performance of a group of leaders.

Fletcher and Käufer (in Pearce \& Conger, 2002) explain "leadership effectiveness in living systems of relationships does not depend on individual, heroic leaders but rather on leadership practices embedded in a system of interdependencies at different levels within the organization" (p. 21). Wang, Waldman, and Zhang (2014) similarly assess the interplay between formal and informal systems, categorizing the latter by dynamic processes of influence, cohesion, and boundary spanning, which results in consensus, coordination, efficiency, and improved performance: social capital is increased, including more extensive knowledge, abilities, and skills, with team information-processing and learning. Liu, Hu, Li, Wang, and Lin (2014) also attribute improved performance to increased psychological safety in being part of a collective. While traditional hierarchies were in place, the dynamic process by which individuals interact reflected the properties of collective leadership: this phenomenon was holistic and an irreducible facet of the response collective (cf. Carson et al., 2007 in Wang et al., 2014).

We note the response effort included hierarchical systems demonstrating collective leadership behaviors. With such "meta-leadership," hierarchical and collective leadership can be complementary processes and mutually supportive when it emphasizes connectivity and the importance of integrating intra- and inter-organizational resources, structures, decisions, and actions (DeRue, 2011; Marcus, Dorn, \& Henderson, 2006; Marcus, Dorn, McNulty, Henderson, $\&$ Ashkenazi, 2012). Leaders have an important role in framing the situation to encourage collective cooperation in sense-making, fostering relationships within networks, disseminating information efficiently, and developing shared mental models, trust, respect, loyalty, and obligations for reciprocity (Combe \& Carrington, 2015; Pearson \& Clair, 1998; Zhang, Waldman, \& Wang, 2012). Failure to do so contributes to conflict and crisis (Pearson \& Clair, 1998). The resultant two-part model offers a compelling counterpoint to both traditional and strictly collective conceptualizations of leadership.

While this body of work provides ample justification for looking beyond models of individual-centric leadership to explain beneficial leadership outcomes, it is not sufficient to explain the specific behavioral norms that established the collective leadership we discovered or its successes. Further, an identified gap in these conceptual models is a "language of competence" (Pearce \& Conger, 2003, p.26) to enable translation of these behaviors into operational principles for prospectively creating the conditions for collective leadership to emerge. We specifically examined this gap in the challenging leadership environment of response to this traumatic event. For deeper model explication, we turned to swarm intelligence (SI) as its study is largely grounded in behavioral observation. 
Swarm Intelligence. SI describes the collective behavior of decentralized, selforganized systems (Miller, 2007; "Swarm Intelligence," n.d.), a phenomenon whereby "two or more individuals independently, or at least partially independently, acquire information and these different packages of information are combined and processed through social interaction, which provides a solution to a cognitive problem in a way that cannot be implemented by isolated individuals" (Krause, Ruxton, \& Krause, 2009, p. 29). Through SI, organisms, either natural or artificial, complete complex tasks by interacting with simple social cues and by following simple rules (Beni \& Wang, 1989; Krause et al., 2009). Therefore, by observing, interacting, and responding in predictable ways, each actor contributes to the success of the whole (Beni \& Wang, 1989; Moussaïd et al., 2011). The emergent organization exemplifies a fascinating phenomenon: as described by Fort (2011), "[s]warm intelligence is a paradigmatic example of self-organization of complex systems that requires no leader or central planning” (p. 243).

We found a similar phenomenon in the Boston response enabling leaders to achieve complex outcomes among multiple hierarchical structures without instituting a formal overall governance structure. As is discussed in greater detail below, extensive inter-agency and crosssector planning and training played the role of evolutionary biology in creating the conditions in which SI was more likely to emerge as well as the shared rules and cues that would guide it. The outcome of this autogenetic organizational process is a synergistic effect whereby many individuals working in concert can accomplish more than they could on their own.

Complex disasters know no jurisdictional, political, or divisional bounds, and the extent of interventions required often dramatically exceeds the capacity and resources of any individual organization. Lichtenstein and Plowman (2009) explain that, "[a]t a critical threshold, when the system has reached the limit of its capacity, it can either collapse or re-organize" (p. 620). Thus, disaster response must capitalize on the strengths and resources of multiple agencies for continuous adaptation and collaboration in the field (Contractor et al., 2012; Friedrich et al., 2014; Yammarino et al., 2012). The question is, will these disparate parties "swarm"—-acting in harmony and synchrony as parts of a collective whole?

Boin \& 't Hart (2003) describe how “...in most large-scale crisis situations, the myth of centralized response structures is sustained by setting up and formally empowering crisis centers, [but] pivotal policy decisions actually emerge from a multi-actor coordination process, in which consultation, negotiation, and outright confrontation are the orders of the day ('t Hart, Rosenthal, \& Kouzmin, 1993). Many dynamic, situation-specific, and urgent problems arise simultaneously at different places and nodes in the response network" (pp. 547-548). When compared to selfcontained, vertically integrated organizations, multi-firm networks are more agile and able to efficiently tailor operations to meet the needs of the current environment (Day, Gronn, \& Salas, 2006; Friedrich et al., 2014; Lichtenstein \& Plowman, 2009; Nicolaides et al., 2014; Snow, Fjeldstad, Lettl, \& Miles, 2011). Therefore, the changing and evolving characteristics of crises (Boin \& 't Hart, 2003) requires a reconceptualization of leadership styles that is similarly flexible, adaptable, and capable of dynamic function that fully capitalizes on its available resources.

The five emergent themes identified through interviews with crisis leaders of the Boston response are consistent with principles of collective leadership and swarm intelligence. These 
themes also identify specific behavioral characteristics that encourage emergence of these phenomena in crisis conditions. When presented with the study findings, the FBI SAC who led the investigation remarked, "They describe exactly what we did though I was not aware of them at the time." The five themes provide a framework to translate theory into pragmatic and actionable best practices. We refer to this interplay between collective leadership and SI as swarm leadership.

Integrating Insights for Swarm Leadership. The insights derived from the interviews demonstrate how collective leadership and SI combine to form swarm leadership, which is the practical application of theoretical concepts in real world situations. The behavioral norms developed within this framework provide the missing language of competence (Pearce \& Conger, 2003) to help leaders successfully translate theory into practice. SI informs the interpretation and understanding of what happened in Boston and the larger challenge of optimizing normative behaviors for multi-team systems (Millikin, Hom, \& Manz, 2010; Murase, Carter, DeChurch, \& Marks, 2014).

Unity of mission. Disasters tend to unite a community (Solnit, 2009). Even so, clearly articulating the mission of the response and uniting participants within a framework is a crucial quality of disaster leadership. Complicating unity of mission across different organizations is the tension between fidelity to individual organizational tasks and simultaneous coordination of actions only accomplished by working together. When the mission is framed to forge a shared mental model (Friedrich et al., 2014; Lichtenstein \& Plowman, 2009; Page, 2010), the seeming tension between the two creates a positive self-reinforcing feedback loop. This sort of diversity enhances the efficacy of SI according to Page's Diversity Prediction Theorem (Page's Theorem) (Fort, 2011; Seeley, Visscher, \& Passino, 2006). Optimal diversity emerges when different perspectives and skill sets enhance cooperative function, however, too much variance may impede cooperativity (Krause et al., 2009). Therefore, when misaligned, tension caused by such variability may result in conflict, wasted resources, and sub-optimal outcomes (Lichtenstein \& Plowman, 2009; Page, 2010; White et al., 2014).

In the Boston response, a clear universal objective aligned the priorities of disparate organizations into a common framework and a shared mental model, and the resultant unity of effort linked the activities of responders and obviated bureaucratic obstructions that typically hinder effective response (White, Currie, \& Lockett, 2014). This unity of effort then culminated in the "cooperative coordinated behavior" typified in SI (Bettencourt, 2009).

Generosity of spirit and action. In crisis, there is little gained for the overall operation from defensive proprietary maneuvers (Murase et al., 2014; White et al., 2014). Leading with generosity of spirit rallies participants to assist one another in overcoming resource limitations and other obstacles. Solidification and reinforcement of the in-group promotes cooperativity (Giannakakis \& Fritsche, 2011) and negates potential challenges that can arise from the diversity of backgrounds among different responder organizations (Millikin et al., 2010; Nicolaides et al., 2014). In turn, this inclination reinforces the efficacy of the collective solution set as Page's Theorem holds without complication. 
Stay in your lane. When groups are differently but compatibly specialized, their unique contributions to the collective reap the most value when they are both independent and also in conformity with the expectations of other agencies (Contractor et al, 2012), supporting a selforganization that respects each other's responsibilities and authority (Goldstone \& Gureckis, 2009). This dynamic has been described as intrinsic to the synergistic functionality of SI (Bettencourt, 2009; Krause et al., 2009; Seeley et al., 2006). There are periodic rivalries among law enforcement agencies and with other emergency response organizations. In the Boston response, they fully recognized and appreciated how their different jurisdictional authorities and operational capacities could complement one another.

Leaders operating to leverage collective intelligence (Woolley, Chabris, Pentland, Hashmi, \& Malone, 2010) identify the strengths of each organization and recognize the jurisdiction and duty of each agency. When respect is assured at the executive leadership level, it supports and encourages cooperation and collaboration between organizations (Millikin et al., 2010). In the Boston response, experience with cross-agency organizational structures, including the Joint Terrorism Task Force, and protocols including the National Incident Management System (NIMS) and the Incident Command System (ICS), established well-demarcated lanes of responsibility and appreciation for each entity's contributions to the overall effort (Lehr, 2012; Federal Emergency Management Agency [FEMA], 2004; FEMA, 2015). These structures and protocols enhanced collaboration and prepared agencies for the multi-jurisdictional response (Leonard, Cole, Howitt, \& Heymann, 2014).

No ego-no blame. Complex crises frequently raise politically motivated, competitive, and ego-driven leader behavior. At times, leaders assert authority to assure the public that someone is "in charge." When a response is succeeding, some leaders are motivated to exploit the success to raise the visibility of their agency. When there are difficulties or deficiencies, they blame others at the expense of the in-group (National Commission on Terrorist Attacks upon the United States, 2004; National Commission on the BP Deepwater Horizon Oil Spill and Offshore Drilling, 2011; Select Bipartisan Committee to Investigate the Preparation for and Response to Hurricane Katrina, 2006). These behaviors divert attention from the primary mission and erode the very trust key to building cooperation (e.g., Krause et al., 2009) and successful collective leadership (Millikin et al., 2010).

Boston response leaders exhibited abundant emotional intelligence (cf., Goleman, 1996; Rosenthal, Twomey, Hartnett, Wu, \& Couzin, 2015) they described as "no ego, no blame." This mutual respect was an asset during meetings that deliberated risk-laden questions as well as during carefully orchestrated press conferences.

Foundation of trusted relationships. Leaders of the Boston response cultivated long term and collaborative relationships garnered through years of joint exercises, drills and responses that included all levels of government as well as the private sector. This reinforced the importance of strong inter-agency collaboration (Junker \& van Dick, 2014; MEMA, 2013; Page, 2010; Yammarino et al., 2012). These shared crucible events fostered a spirit of cooperation, creating the solidarity of an "in-group" (e.g., Giannakakis \& Fritsche, 2011) that was further enriched by long tenures of these executive leaders. This strong foundation of trusted relationships encouraged them to appreciate and respect each agency's contributions (Serino, 
2013). These leaders were comfortable with and confident in one another. One participant said, "We don't just know each other's names. We know what sports each other's kids play." The resulting familiarity, trust, and confidence fostered a collective leadership mindset.

Moussaïd, Garnier, Theraulaz, and Helbing (2009) explain that with SI, “ . . selforganizing processes require multiple direct or indirect interactions among individuals to produce a higher-level, aggregate outcome. Repeated interactions among group members are the heart of any self-organized dynamics" (p. 473).

These leaders coalesced an effective emergency response network by creating a strong foundation of trusted relationships, unifying under a single mission, being generous in spirit and action, staying in their lanes, and exhibiting no-ego-no-blame behavior. The collective leadership model was self-reinforcing. Throughout the Boston response, the benefits of collective leadership were clear, highlighting the advantages of integrating, teaching and leveraging collective leadership practices before a crisis hits.

In order to integrate these insights for swarm leadership into leadership education or training curriculum, the authors most often teach the principles of swarm leadership using a combination of didactic material and case-based discussion. The first didactic segment presents the three dimensions of the meta-leadership framework (Marcus et al., 2006; Marcus et al., 2012). Dimension One is The Person which introduces individual behavioral elements. Dimension Two is the Situation which explores context-specific challenges for leaders. Dimension Three is Connectivity which includes interpersonal and organizational behavior elements. The second didactic segment introduces the basic elements of swarm intelligence outlined above. This is followed by an overview and open discussion of the Boston Marathon bombing response as a case example of swarm leadership, with an emphasis on cooperativity at critical decision points as a vehicle for understanding how to integrate and apply the didactic material. An appreciation for the principles of swarm leadership and how to develop and integrate them into leadership training and practice emerge through this discussion.

\section{Limitations and Recommendations for Further Research}

Inquiry into the crisis leadership lessons learned during the Boston response suggests it may be possible to replicate similar collective leadership in other crises. A larger, heterogeneous sample would be necessary to confirm the analyses and to test generalizability; one event is inherently limiting in discerning the general applicability of findings. Similarly, a larger sample would contribute to further model development, especially as perspectives of these events may vary.

We also note the opportunity for follow-up analyses to test replicability. This is a case study based upon local events. Research with different in-group/out-group affiliations and perspectives would lend valuable comparative analysis to raise possible confirmation, selection, belief, or other relevant biases. As is true of any self-report data, individual perspective plays a key role in informing the outcome: interviewee perspectives are shaped by personal experience and prior training, informing expectations and even information-assimilation during the event; perspectives change as a function of experience with the event; finally, recollections are subject 
to change after the event with multiple retellings and application of coping strategies after extreme events. Individual recollections are also subject to fundamental attribution error, selfserving bias, and hindsight bias. Interactions with the world are contingent on how it is perceived, not on how objective it "is" (McAdams \& McLean, 2013).

The impact of these mechanisms on how participants processed their experiences of the Boston response and how they shape future actions and interactions will be an important extension of our analysis. It is possible to analyze retroactively other complex crisis responses through the lens of SI and collective leadership, prospectively in exercises and drills, as well as through observational research during actual incidents to validate, refine, or refute the model we propose as the foundation for the leadership of the Boston response.

\section{Conclusion}

In the Boston response, the distinctive degree of inter-agency connectivity resulted from substantial preparation and the cooperative tone set by key leaders. Numerous agencies worked effectively together to generate order beyond the constraints of any over-arching command-andcontrol structure. This phenomenon fostered diversity without divergence. Strong situational awareness emerged through direct communication and reliable coordination. Facing critical lifeand-death circumstances, the leaders "swarmed" to achieve a remarkable outcome.

This study thus contributes to both theory development and practice improvement by identifying five behavioral themes critical to the emergence of collective leadership and utilizing swarm intelligence to form its missing "language of competence." We call this confluence of theory and practice swarm leadership. The evidence suggests that swarm leadership does not appear by chance. Robust protocols, procedures and policies, honed through training, exercises, and actual responses, offered leaders in Boston the opportunity improve operational cooperativity and build individual and organizational relationships from which swarm leadership emerged. Intentional deployment of the five behaviors by leaders may improve the chances of is emergence in other crises. 


\section{References}

Ancona, D. \& Backman, E. (2010a). Distributed leadership: Going from pyramids to networks. Leadership Excellence, 27(1), 11-12.

Ancona, D. \& Backman, E. (2010b). It's not all about you. Harvard Business Review. Retrieved from https://hbr.org/2010/04/its-not-all-about-me-its-all-a

Ancona, D., Bresman, H., \& Caldwell, D. (2009). The X-factor: Six steps to leading highperforming X-teams. Organizational Dynamics, 38(3), 217-224.

Benbasat, I., Goldstein, D. K., \& Mead, M. (1987). The case research strategy in studies of information systems. MIS Quarterly, 11(3), 369-386.

Beni, G., \& Wang, J. (1989, June). Swarm intelligence in cellular robotic systems. Proceedings of the NATO Advanced Workshop on Robots and Biological Systems. Tuscany, Italy.

Bettencourt, L. M. A. (2009). The rules of information aggregation and emergence of collective intelligent behavior. Topics in Cognitive Science, 1, 598-620. doi:10.1111/j.17568765.2009.01047.x

Boin, A., \& 't Hart, P. (2003). Public leadership in times of crisis: Mission impossible? Public Administration Review, 63(5), 544-553.

Buchanan, D. A., \& Bryman, A. (Eds.). (2011). The SAGE handbook of organizational research methods. Los Angeles, CA: SAGE Publications, Inc.

Combe, I. A., \& Carrington, D. J. (2015). Leaders' sensemaking under crises: Emerging cognitive consensus over time within management teams. The Leadership Quarterly, 26, 307-322. doi: 10.1016/j.leaqua.2015.02.002

Contractor, N. S., DeChurch, L. A., Carson, J., Carter, D. R., \& Keegan, B. (2012). The topology of collective leadership. The Leadership Quarterly, 23, 994-1011. doi: 10.1016/j.leaqua.2012.10.010

Creswell, J. W. (2014). Research design: Qualitative, quantitative, and mixed methods approaches ( $4^{\text {th }}$ ed.). Los Angeles, CA: SAGE Publications, Inc.

Daniel, J. (2011). Sampling essentials: Practical guidelines for making sampling choices. Los Angeles, CA: SAGE Publications, Inc.

Day, D. V., Gronn, P., \& Salas, E. (2006). Leadership in team-based organizations: On the threshold of a new era. The Leadership Quarterly, 17, 211-216. doi:

10.1016/j.leaqua.2006.02.001. 
DeRue, D. S. 2011. Adaptive leadership theory: Leading and following as a complex adaptive process. Research in Organizational Behavior, 31, 125-150.

doi:10.1016/j.riob.2011.09.007

D'Innocenzo, L., Mathieu, J. E., \& Kukenberger, M. R. (2014). A meta-analysis of different forms of shared leadership-team performance relations. Journal of Management, 20(10), $1-28$.

Drescher, M. A., Korsgaard, M. A., Welpe, I. M., Picot, A., \& Wigand, R. T. (2014). The dynamics of shared leadership: Building trust and enhancing performance. Journal of Applied Psychology, 99(5), 771-783. doi: 10.1037/a0036474.

Eisenhardt, K. M. (1989). Building theories from case study research. Academy of Management Review, 14, 532-550.

Edmondson, A. (2012). Teaming: How organizations learn, innovate, and compete in the knowledge economy. John Wiley \& Sons: Hoboken, NJ.

Federal Emergency Management Agency. (2004). NIMS and the Incident Command System. Retrieved from FEMA website: http://www.fema.gov/txt/nims/nims_ics_position_paper.txt.

Federal Emergency Management Agency. (2013). Boston marathon bombings: The positive effects of planning and preparation on response. Retrieved from https://www.llis.dhs.gov/sites/default/files/Boston\%20Marathon\%20Bombings\%20Positi ve\%20Effects\%20of\%20Preparedness_0.pdf

Federal Emergency Management Agency. (2015). National Incident Management System implementation. Retrieved from https://www.fema.gov/national-incident-managementsystem/implementation-guidance-and-reporting

Fort, H. A. (2011). Simple rules for complex collective behavior [Review of the book The perfect swarm: The science of complexity in everyday life by Len Fisher]. The American Journal of Psychology, 124(2), 243-247. doi: 10.5406/amerjpsyc.124.2.0243

Friedrich, T. L., Vessey, W. B., Schuelke, M. J., Mumford, M. D., Yammarino, F. J., \& Ruark, G. A. (2014). Collectivistic leadership and George C. Marshall: A historiometric analysis of career events. The Leadership Quarterly, 25, 449-467. doi:

10.1016/j.leaqua.2013.10.012

Giannakakis, A. E. \& Fritsche, I. (2011). Social identities, group norms, and threat: On the malleability of ingroup bias. Personality and Social Psychology Bulletin, 37(1), 82-93.

Gibbert, M., \& Ruigrok, W. (2010). The "what" and "how" of case study rigor: Three strategies based on published work. Organizational Research Methods, 13(4), 710-737. 
Gibson, C. (2001). Knowledge accumulation to accommodation: Cycles of collective cognition in work groups. Journal of Organizational Behavior, 22(2): 121-134. doi: 10.1002/job.84

Glaser, B. G. (2009). The novice GT researcher. The Grounded Theory Review, 8(2), 1-21.

Glaser, B., \& Strauss, A. (1967). The discovery of grounded theory: Strategies for qualitative research. Chicago, IL: Aldine.

Goldstone, R.L. \& Gureckis, T.M. (2009). Collective behavior. Topics in cognitive science, 1, 412-438.

Goleman, D. (1996). Emotional intelligence: Why it can matter more than IQ. New York: Bantam Dell.

Goralnick, E., Halpern, P., Loo, S., Gates, J., Biddinger, P., Fisher, J., . .Peleg, K. (2015). Leadership during the Boston Marathon bombings: A qualitative after-action review. Disaster Medicine and Public Health Preparedness. doi:10.1017/dmp.2015.42.

Goulding, C. (2009). Grounded theory perspectives in organizational research. In D. Buchanan and A. Bryman (Eds), The Sage handbook of organizational research methods (pp. 381394). Los Angeles, CA: SAGE Publications, Inc.

Hadley, C. N., Pittinsky, T. L., Sommer, S. A., \& Zhu, W. (2011). Measuring the efficacy of leaders to assess information and make decisions in a crisis: The C-LEAD scale. The Leadership Quarterly, 22, 633-648. doi: 10.1016/j.leaqua.2011.05.005

Junker, N. M. \& van Dick, R. (2014). Implicit theories in organizational settings: A systematic review and research agenda of implicit leadership and followership theories. The Leadership Quarterly, 25, 1154-1173. doi:10.1016/j.leaqua.2014.09.002

King, A. J. \& Sumpter, D. J. T. (2012). Murmurations. Current Biology, 22(4): R112-114.

Krause, J., Ruxton, G.D., \& Krause, S. (2009). Swarm intelligence in animals and humans. Trends in Ecology and Evolution, 25(1), 28-34. doi: 10.1016/j.tree.2009.06.016

Lehr, R. (2012). Emergency response: An overview. In Kamien, D. (Ed.) The McGraw Hill Homeland Security Handbook: Strategic Guidance for a Coordinated Approach to Effective Security and Emergency Management, $2^{\text {nd }}$ edition. McGraw-Hill: New York.

Leonard, H., Cole, C., Howitt, A., \& Heymann, P. (2014). Why was Boston Strong?: Lessons from the Boston Marathon Bombing. Retrieved from Harvard Kennedy School Program on Crisis Leadership website: http://www.hks.harvard.edu/content/download/67476/1242714/version/1/file/WhyWasBo stonStrong.pdf 
Leonard, H. B. \& Howitt, A. M. (2012). Working together in crises. Crisis Response, 7(4). Retrieved from http://www.hks.harvard.edu/content/download/67398/1242402/version/1/file/Working+T ogether+in+Crises--CRJ+March+2012.pdf

Leonard, H. B. \& Howitt, A. M. (2013). Boston Marathon bombing response. Crisis Response Journal, 8(4), 18-21.

Lichtenstein, B. B. \& Plowman, D. A. (2009). The leadership of emergence: A complex systems leadership theory of emergence at successive organizational levels. The Leadership Quarterly, 20, 617-630. doi: 10.1016/j.leaqua.2009.04.006

Lincoln, Y.S., \& Guba, E. (1985). Naturalistic inquiry. Beverly Hills, CA: Sage Publications.

Liu, S., Hu, J., Li, Y., Wang, Z., \& Lin, X. (2014). Examining the cross-level relationship between shared leadership and learning in teams: Evidence from China. The Leadership Quarterly, 25, 282-295. doi:10.1016/j.leaqua.2013.08.006

Marcus, L. J., Dorn, B. C., \& Henderson, J. M. (2006). Meta-leadership and national emergency preparedness: A model to build government connectivity. Biosecur Bioterror, 4(2), 128134. doi:10.1089/bsp.2006.4.128

Marcus, L., Dorn, B., McNulty, E., Henderson, J., \& Ashkenazi, I. (2012). Crisis preparedness and response: The meta-leadership model. In Kamien, D. (Ed.), The McGraw-Hill Homeland Security Handbook: The definitive guide for law enforcement, EMT, and all other security professionals (679-710). New York: McGraw-Hill.

Marcus, L., McNulty, E., Dorn, B., \& Goralnick, E. (2014). Crisis meta-leadership lessons from the Boston Marathon bombing response: the ingenuity of swarm intelligence (White Paper). Retrieved from Harvard University, National Preparedness Leadership Initiative website: https://cdn2.sph.harvard.edu/wp-content/uploads/sites/8/2014/04/April-2014Prelim-Report-Dist1.pdf

Martin, P. Y. \& Turner, B. A. (1986). Grounded theory and organizational research. The Journal of Applied Behavioral Science, 22(2), 141-157.

Massachusetts Emergency Management Agency (2013, June). MEMA reports, 12(6). Retrieved from http://www.mass.gov/eopss/docs/mema/mema-reports/mema-reports-12-6.pdf

Massachusetts Emergency Management Agency, Massachusetts Department of Public Health, City of Boston, City of Cambridge, Town of Watertown, Massachusetts Bay Transportation Authority Transit Police Department, ... Massachusetts State Police. (2014). After action report for the response to the 2013 Boston Marathon bombings. Retrieved from http://www.mass.gov/eopss/docs/mema/after-action-report-for-theresponse-to-the-2013-boston-marathon-bombings.pdf 
McAdams, D. P., \& McLean, K. C. (2013). Narrative identity. Current Directions in Psychological Science, 22(3), 233-238. doi: 10.1177/0963721413475622

Miller, P. (2007). The genius of swarms. National Geographic. Retrieved on July 1, 2014 from http://ngm.nationalgeographic.com/2007/07/swarms/miller-text

Millikin, J. P., Hom, P. W., \& Manz, C. C. (2010). Self-management competencies in selfmanaging teams: Their impact on multi-team system productivity. The Leadership Quarterly, 21, 687-702. doi:10.1016/j.leaqua.2010.07.00

Moussaïd, M., Garnier, S., Theraulaz, G., \& Helbing, D. (2009). Collective information processing and pattern formation in swarms, flocks, and crowds. Topics in Cognitive Science, 1, 469-497.

Moussaïd, M., Helbing, D., \& Theraulaz, G. (2011). How simple rules determine pedestrian behavior and crowd disasters. PNAS, 108(17), 6884-6888. doi:10.1073/pnas.1016507108

Murase, T., Carter, D. R., DeChurch, L. A., \& Marks, M. A. (2014). Mind the gap: The role of leadership in multiteam system collective cognition. The Leadership Quarterly, 25, 972986. doi: 10.1016/j.leaqua.2014.06.003

National Commission on Terrorist Attacks upon the United States (2004). The 9/11 commission report. Retrieved from http://www.9-11 commission.gov/report/911Report.pdf

National Commission on the BP Deepwater Horizon Oil Spill and Offshore Drilling (2011). Deep water: The Gulf oil disaster and the future of offshore drilling. Retrieved from http://www.gpo.gov/fdsys/pkg/GPO-OILCOMMISSION/pdf/GPOOILCOMMISSION.pdf

National Preparedness Leadership Initiative (NPLI) (2013). Executive development. Retrieved from https://npli.sph.harvard.edu/executive-development/

Neffenger, P., \& McNulty, E. (2012, December 6). The Deepwater Horizon oil spill: A case discussion. Presented at the National Preparedness Leadership Initiative Executive Education Program at Harvard University, Cambridge, MA.

Nicolaides, V. C., LaPort, K. A., Chen, T. R., Tomassetti, A. J., Weis, E. J., Zaccaro, S. J., \& Cortina, J. M. (2014). The shared leadership of teams: A meta-analysis of proximal, distal, and moderating relationships. The Leadership Quarterly, 25, 923-942. Doi: 10.1016/j.leaqua.2014.06.006

Orr, J. E. (1996). Talking about machines: An ethnography of a modern job. Ithaca, NY: Cornell University Press.

Packer, M. (2010). The science of qualitative research. Cambridge: Cambridge University Press. 
Page, S. (2010). Integrative leadership for collaborative governance: Civic engagement in Seattle. The Leadership Quarterly, 21, 246-263. doi:10.1016/j.leaqua.2010.01.005

Pearce, C. L., \& Conger, J. A. (2003). Shared leadership: Reframing the hows and whys of leadership. New York: Sage Publications, Inc.

Pearson, C. M., \& Clair, J. A. (1998). Reframing crisis management. Academy of Management Review, 23(1), 59-76. doi:10.2307/259099

Purposive sampling. (n.d.) In Laerd Dissertation, Lund Research, Ltd. (2012). Retrieved from http://dissertation.laerd.com/purposive-sampling.php

Robert, B., \& Lajtha, C. (2002). A new approach to crisis management. Journal of Contingencies and Crisis Management, 10(4), 181-191.

Rolling, Jr., J. H. (2013). Swarm intelligence: What nature teaches us about shaping creative leadership. Palgrave Macmillan: Basingstroke, Hants, United Kingdom.

Rosenthal, S. B., Twomey, C. R., Hartnett, A. T., Wu, H. S., \& Couzin, I. D. (2015). Revealing the hidden networks of interaction in mobile animal groups allows prediction of complex behavioral contagion. PNAS, 112(15), 4690-4695. doi:10.1073/pnas.1420068112

Rouse, W. \& Morris, N. (1986). On looking into the black box: Prospects and limits in the search for mental models. Psychological Bulletin, 100(3): 349-363. doi:10.1037/0033-2909.100

Schoenberg, A. L. (2004). What it means to lead during a crisis: An exploratory examination of crisis leadership. Chapter proposal, S.I. Newhouse School of Public Communications, Syracuse University, Syracuse, NY.

Schutt, R. K. (2015). Investigating the social world: The process and practice of research $\left(8^{\text {th }}\right.$ ed.). Los Angeles, CA: SAGE Publications, Inc.

Seeley, T. D., Visscher, P. K., \& Passino, K. M. (2006). Group decision making in honey bee swarms. American Scientist, 94, 220-229.

Select Bipartisan Committee to Investigate the Preparation for and Response to Hurricane Katrina (2006). A failure of initiative: Final report of the Select Bipartisan Committee to Investigate the Preparation for and Response to Hurricane Katrina. Retrieved from http://www.gpo.gov/fdsys/pkg/CRPT-109hrpt377/pdf/CRPT-109hrpt377.pdf

Serino, R. (2013). Lessons learned from the Boston Marathon bombings: Preparing for and responding to the attack. Retrieved from FEMA website: http://www.fema.gov/medialibrary-data/20130726-1923-25045-

1176/lessons_learned_from_the_boston_marathon_bombings_preparing_for_and_respon ding_to_the_attack.pdf 
Snow, C., Fjeldstad, O., Lettl, C., \& Miles, R. (2011). Organizing continuous product development and commercialization: The collaborative community of firms model. Journal of Product Innovation Management, 28, 3-16.

Solnit, R. (2009). A paradise built in Hell: The extraordinary communities that arise in disaster. New York: Penguin.

Swarm Intelligence. (n.d.) In Wikipedia. Retrieved February 9, 2015 from http://en.wikipedia.org/wiki/Swarm_intelligence

Wang, D., Waldman, D. A., \& Zhang, Z. (2014). A meta-analysis of shared leadership and team effectiveness. Journal of Applied Psychology, 99(2), 181-198. doi: 10.1037/a0034531

White, L., Currie, G., \& Lockett, A. (2014). The enactment of plural leadership in a health and social care network: The influence of institutional context. The Leadership Quarterly, 25, 730-745. doi: 10.1016/j.leaqua.2016.01.004

Woolley, A. W., Chabris, C. F., Pentland, A., Hashmi, N., \& Malone, T. W. (2010). Evidence for a collective intelligence factor in the performance of human groups. Science, 330, 686688. doi: $10.1126 /$ science. 1193147

Yammarino, F. J., Salas, E., Serban, A., Shirreffs, K., \& Shuffler, M. L. (2012). Collectivistic leadership approaches: Putting the "we" in leadership science and practice. Industrial and Organizational Psychology, 5, 382-402. doi: 10.1111/j.1754-9434.2012.01467.x

Zhang, Z., Waldman, D. A., \& Wang, Z. (2012). A multilevel investigation of leader-member exchange, informal leader emergence, and individual and team performance. Personnel Psychology, 65(1), 49-78. doi:10.1111/j.1744-6570.2011.01238.x

\section{Author Biographies}

Eric J. McNulty, M.A. is Director of Research and Professional Programs at NPLI and teaches numerous graduate-level courses on leadership and negotiation at Harvard Chan. Mr. McNulty is a former editor at large and director of conferences at Harvard Business Publishing. He has written for Harvard Business Review and other leading publications. emcnulty@hsph.harvard.edu

Barry C. Dorn, M.D., M.P.H.M. is Associate Director of NPLI and the Program for Health Care Negotiation and Conflict Resolution at Harvard Chan. He is a Clinical Professor of Orthopedic Surgery at the Tufts University School of Medicine and is on the faculty of Health Science at Ben-Gurion University of the Negev, Israel. bcdorn@ hsph.harvard.edu 
Eric Goralnick, M.D., M.S. serves as Medical Director of Emergency Preparedness at Brigham and Women's Healthcare. He is an Assistant Professor of Emergency Medicine at Harvard Medical School and an instructor at Harvard Chan. Dr. Goralnick is a veteran of the US Navy and a 1995 graduate of the US Naval Academy. egoralnick@ partners.org

Richard Serino is a Distinguished Visiting Fellow with NPLI, where he participates in myriad leadership education and research initiatives. The former Deputy Administrator of FEMA and Chief of Boston EMS, Mr. Serino has more than 40 years' experience in disaster preparedness, response and recovery, and leadership and innovation in government.

Jennifer O. Grimes, M.A., M.D. Candidate, is a medical student at Brown University's Warren Alpert Medical School. Prior to medical school, Ms. Grimes served as Research Coordinator for the BIDMC Fellowship in Disaster Medicine. She completed her M.A. in Interdisciplinary Studies of Neuroscience, Psychology and Philosophy at the University of Central Florida in 2010. jgrimes@wellesley.edu

Lisa Borelli Flynn, J.D., M.P.H. earned her M.P.H. at Harvard Chan in 2016, after which she joined NPLI as a Research Associate. Previously, she worked in Healthcare Quality and Patient Safety at Beth Israel Deaconess Hospital-Needham. Ms. Flynn was an associate at a large Boston law firm before joining the health care field. lif992@mail.harvard.edu

Melani Cheers, MD serves as Director of Health Services at Ross University School of Medicine. She received her M.P.H. from Harvard Chan in 2015. Previously, she practiced Emergency Medicine at major medical centers in Massachusetts and Pennsylvania. Dr. Cheers graduated from Washington University School of Medicine in St. Louis in 2009.

mscheers@gmail.com

Leonard J. Marcus, PhD is founding Co-Director of NPLI and founding Director of the Program for Health Care Negotiation and Conflict Resolution at Harvard Chan. Dr. Marcus teaches numerous courses on leadership and negotiation at Harvard Chan and serves on the faculty of Health Sciences at Ben-Gurion University of the Negev, Israel.

ljmarcus@hsph.harvard.edu 